\title{
Vorwort des Übersetzers
}

Hiermit lege ich Paul Tillichs bekannte Schrift „Dynamics of Faith“ von 1957, die eine sehr gute Einführung in sein religionsphilosophisches Denken der amerikanischen Zeit bietet, in einer neuen Übersetzung und mit einem Kommentar vor. Eine Neuübersetzung war längst überfällig, da die beiden bestehenden deutschen Übersetzungen ausgesprochen defizient sind. Dadurch, dass ich nicht nur auf den englischen Erstdruck zurückgegriffen habe, sondern auch Tillichs handschriftliches Manuskript und das für den Druck erstellte Typoskript zu Rate gezogen habe, konnte ich eine ganze Reihe von zum Teil sehr grober Fehlern des Erstdrucks korrigieren, und so ist diese deutsche Neuübersetzung authentischer als der englische Erstdruck.

Ich habe Freunden und Kollegen zu danken, die mir während des Übersetzungsprozesses mit Rat und Tat zur Seite gestanden haben. Hier sind besonders zu nennen: Uta Glück, Dr. Wolfgang Meiers sowie Pfr.i.R. Klaus Niewerth. Für wertvolle Hinweise und besonders für das Korrekturlesen bin ich meiner wissenschaftlichen Mitarbeiterin Dipl.-Theol. Christina Saal und meiner studentischen Hilfskraft stud. theol. Katharina Wilwers zu Dank verpflichtet.

Dem Verlag Harper, New York, habe ich für die Übertragung der Rechte für diese deutsche Neuübersetzung zu danken, dem Verlag Walter de Gruyter für die Aufnahme dieser Neuübersetzung in sein Programm im Rahmen seiner Reihe „Texte“. An dieser Stelle möchte ich ganz besonders Dr. Albrecht Döhnert, dem Lektor des Verlags Walter de Gruyter, für die fruchtbare und unkomplizierte $\mathrm{Zu}$ sammenarbeit in den vergangenen Jahren danken.

Möge diese Neuübersetzung von Tillichs Schrift „Dynamics of Faith“ eine weite Verbreitung finden und im positiven Sinne „Unruhe“ stiften nicht nur bei jenen, die sich selbst noch für gläubig halten. 
